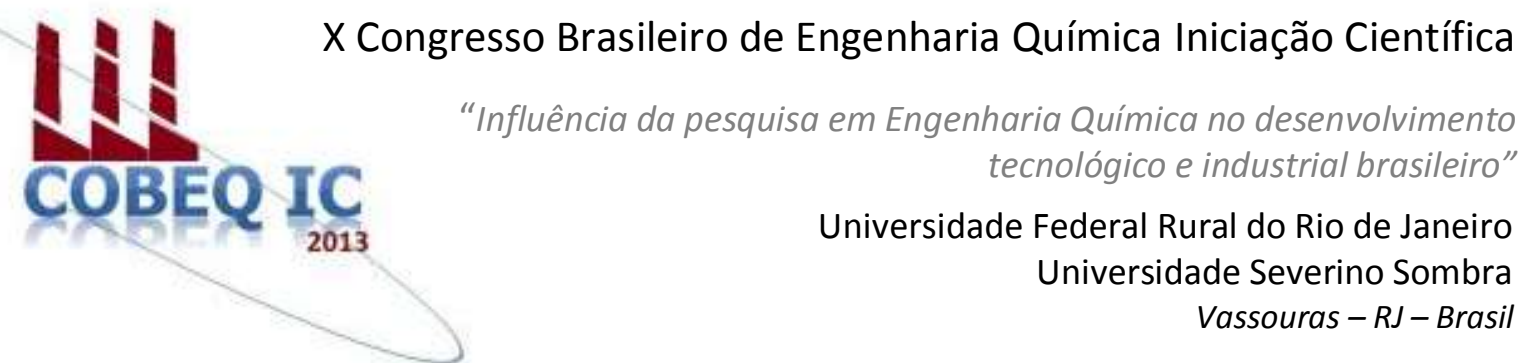

\title{
EQUÍLIBRIO LÍQUIDO-VAPOR DO SISTEMA ETANOL-ÁGUA-GLICEROL: MEDIDAS EXPERIMENTAIS A BAIXA PRESSÃO
}

\author{
SILVA $^{1}$, C. S.; MOREIRA ${ }^{1}$, M. C.; SOUZA ${ }^{2}$, W. L. R.; MENDES $^{3}$, M. F. \\ ${ }^{1}$ Aluno do DEQ/UFRRJ ${ }^{2}$ Mestrando do DEQ/UFRRJ ${ }^{3}$ Professor da DEQ/UFRRJ \\ Departamento de Engenharia Química - Universidade Federal Rural do Rio de Janeiro \\ UFRRJ, BR 465, km 07, Seropédica, CEP. 23.890-000, RJ \\ email: marisamf@ufrrj.br
}

\begin{abstract}
RESUMO - A produção de etanol anidro, em virtude da presença do azeótropo, é difícil usando como processo de separação a destilação convencional. Neste caso, é necessário acrescentar um terceiro componente na destilação. Neste trabalho, o objetivo é usar glicerol como o terceiro componente, integrando o processo de produção de etanol, com a produção de biodiesel, gerando uma biorrefinaria. Por isso, foi desenvolvido um estudo para avaliar o efeito do glicerol no equilíbrio líquido-vapor entre a água e etanol. Os dados experimentais foram medidos, em triplicata, sob pressão normal, em um ebuliômetro, similar ao de Othmer. As análises das amostras foram feitas em um densímetro digital. O valor máximo dos desvios médios não atingiu 5\% em temperatura e composição da fase vapor. Devido aos baixos desvios, os novos dados foram medidos com soluções de etanol-água em diferentes concentrações molares $(0,1$ a 0,9$)$ e taxas diferentes de solvente/alimentação de 0,5, 0,7 e 0,9, para avaliar o comportamento dos dados de equilíbrio do sistema de água-etanol-glicerol. Os resultados mostraram que o glicerol é um solvente promissor porque consegue "quebrar" o azeótropo entre água e etanol e as taxas elevadas de solvente/alimentação enriqueceram mais o etanol na fase vapor.
\end{abstract}

Palavras chave: destilação, ebuliômetro, azeótropo.

\section{INTRODUÇÃO}

A produção e utilização do etanol como combustível ajuda a reduzir as emissões de gases causadores de efeito estufa em até $90 \%$, em comparação com a gasolina. Esse fato deve-se a sua queima ser limpa. Somado a isso, o Brasil, que produz etanol a partir de cana-de-açúcar, é o maior produtor de canade-açúcar do mundo, com 569 milhões de toneladas produzidas na safra 2008/2009, de acordo com a União das Indústrias de CanaDe-Açúcar (2009).

Atualmente, por preocupações ambientais e de segurança energética, novamente o etanol aparece como opção de energia. Em 2008, o percentual de carros flex chegou a $90 \%$. Com isso, o país registrou um consumo de etanol superior ao da gasolina (Agência Safra, 2009 apud Soares, 2010).

O etanol, além de ser um substituto da gasolina e um aditivo da mesma em 
substituição ao chumbo, ainda pode ser utilizado como reagente na produção de biodiesel. Em ambas as aplicações, deve ser utilizado etanol anidro, isento de água. Em adição, é utilizado na síntese de vários outros insumos químicos e o seu uso doméstico é bastante difundido. De posse dessas informações, é fácil verificar que a separação de misturas água-etanol é de grande interesse na indústria (Ravagnani et al., 2010).

A separação dos componentes de uma mistura é de grande importância na indústria química, sendo a destilação o método de separação mais usado atualmente. Algumas misturas, no entanto, apresentam características que dificultam ou, até mesmo, impedem a total separação dos seus componentes. São os casos dos sistemas, cujos pontos de ebulição são muito próximos ou possuem pontos de azeótropo, como a mistura etanol-água, por exemplo. Em composições próximas a 0,88 em etanol (base molar), o sistema forma um azeótropo e a obtenção de um produto mais concentrado se torna impossível através do processo de destilação convencional.

Diante disso, surge o interesse na separação do sistema etanol-água, apesar da obtenção do álcool puro ser difícil através do processo de destilação convencional devido à formação do azeótropo. Porém, Gil et al. (2008) mencionaram que existem alguns processos para a desidratação do etanol: destilação azeotrópica com benzeno, ciclohexano ou pentano; destilação extrativa com agentes líquidos e/ou sais; adsorção com peneiras moleculares e uso de membranas. Vale ressaltar que, segundo Uyazan et al. (2006), uma das técnicas mais usadas na indústria é a destilação extrativa, devido aos menores gastos energéticos e menores custos de investimento e operação.

A destilação extrativa é o processo em que um solvente com alto ponto de ebulição é adicionado ao sistema e altera a volatilidade relativa dos componentes. Isto permite que uma determinada separação seja atingida com um número de estágios menor do que os necessários numa destilação comum, além de promover o deslocamento e a 'quebra' de azeótropos. A Figura 1 mostra uma ilustração do efeito de um solvente qualquer no equilíbrio líquido vapor do sistema etanolágua, com a 'quebra' do azeotropo.

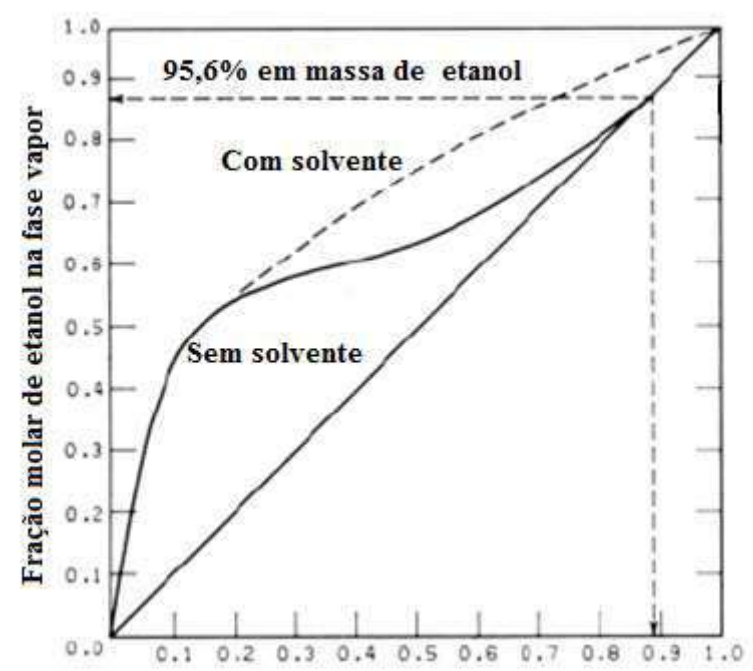

Fração molar de etanol na fase líquida

Figura 1 - Dados de ELV para o sistema águaetanol com e sem a influência de um solvente (Adaptado de Lee e Pahl, 1985)

Para as misturas que apresentam azeótropos, como a mistura etanol-água, a total separação dos componentes requer a adição de uma terceira substância na coluna de destilação, capaz de alterar o equilíbrio líquido-vapor da mistura. Normalmente, a substância adicionada é um solvente e este tipo de destilação é denominado destilação extrativa ou azeotrópica, a depender da volatilidade do mesmo.

O solvente escolhido não deve formar azeótropo com os componentes do sistema e vale lembrar que vários solventes foram propostos e substituídos ao longo dos anos, sempre com o objetivo de economizar energia ou substituir um composto tóxico. A glicerina é capaz de 'quebrar' o azeótropo etanol-água, além de ser um solvente de baixo custo, pode ser de origem renovável e que pode substituir o composto atual, o etileno-glicol, que é derivado do petróleo e levemente tóxico (Ravagnani et al. 2010). Devido a isso, este trabalho propõe a utilização do glicerol para a desidratação do etanol. Atualmente, além de todas as vantagens, o glicerol é um subproduto do biodiesel e o aumento da oferta deste biocombustível lança o desafio de encontrar destino para essa grande quantidade.

Os sistemas água-etanol-glicerol não possuem dados de equilíbrio disponíveis na 
literatura para diferentes proporções de glicerol, sendo estes dados imprescindíveis para a síntese, projeto e otimização do processo. Ao trabalhar com colunas recheadas, por exemplo, a determinação do HETP (altura equivalente a um estagio teórico) depende do conhecimento dos dados de equilíbrio, visto que estudos de cálculos de altura da seção recheada e projetos de colunas de destilação industriais poderão ser feitos, usando-se modelos termodinâmicos bem definidos de acordo com o comportamento do equilíbrio de fases estudado. Sendo assim, este trabalho teve como objetivo medir dados de equilíbrio líquido-vapor do sistema água-etanol na presença de glicerol, a pressão atmosférica.

\section{MATERIAIS E MÉTODOS}

\section{Materiais}

Os reagentes utilizados no preparo das soluções estudadas foram obtidos da Vetec Química Fina (Rio de Janeiro). Utilizou-se glicerol P.A. (dosagem mínima 99,5\%), etanol absoluto (dosagem mínima 99,8\%) e água destilada. Trabalhou-se com soluções de etanol-água nas frações molares de 0,1 a 0,9 em etanol e a relação solvente/carga $(\mathrm{S} / \mathrm{F})$ de 0,5, 0,7 e 0,9 em peso. $\mathrm{O}$ valor de $\mathrm{S}$ (solvente: glicerol)/F (carga: solução etanol-água) foi escolhido com base no trabalho de Furter (1974), que afirmou que os agentes separadores líquidos, neste caso o glicerol, geralmente estão presentes entre 50 e $90 \%$ da fase líquida.

Algumas propriedades físico-químicas do etanol e da água foram medidas e comparadas com as da literatura e podem ser vistas na Tabela 1.

Tabela 1 - Propriedades físico-químicas dos componentes puros medidos neste trabalho

\begin{tabular}{l|c|c|c|c}
\hline & Origem & $\begin{array}{c}\text { Pureza } \\
(\%)\end{array}$ & $\begin{array}{c}\mathrm{Tb} \\
(\mathrm{K})\end{array}$ & $\begin{array}{c}\mathrm{n}_{\mathrm{D}} \\
(298,15 \mathrm{~K})\end{array}$ \\
\cline { 1 - 4 } Etanol & \multirow{3}{*}{ Vetec } & $>99,8$ & 351,65 & 1,3596 \\
\cline { 3 - 5 } & & 100,0 & 373,15 & 1,3325 \\
\hline Água &
\end{tabular}

$\mathrm{T}_{\mathrm{b} \text { etanol }}(\mathrm{K})-351,65$ (Lide \& Frederikse, 1991)

$\mathrm{T}_{\mathrm{b} \text { água }}(\mathrm{K})-373,15$ (Riddick et al., 1986)

$\mathrm{n}_{\text {D etanol }}-1,35941$ (Riddick et al., 1986)

$\mathrm{n}_{\mathrm{D} \text { água }}-1,33250$ (Riddick et al., 1986)

\section{Aparato experimental}

Foram feitos experimentos a pressão atmosférica, utilizando-se um ebuliômetro semelhante ao de Othmer, com dois condensadores, feito de vidro de borosilicato, concebido em laboratório, com base em outras obras e bem trabalhado para outros sistemas estudados anteriormente (benzeno-tolueno $\mathrm{e}$ benzeno-heptano), sobre uma placa de aquecimento, como mostra a Figura 2.

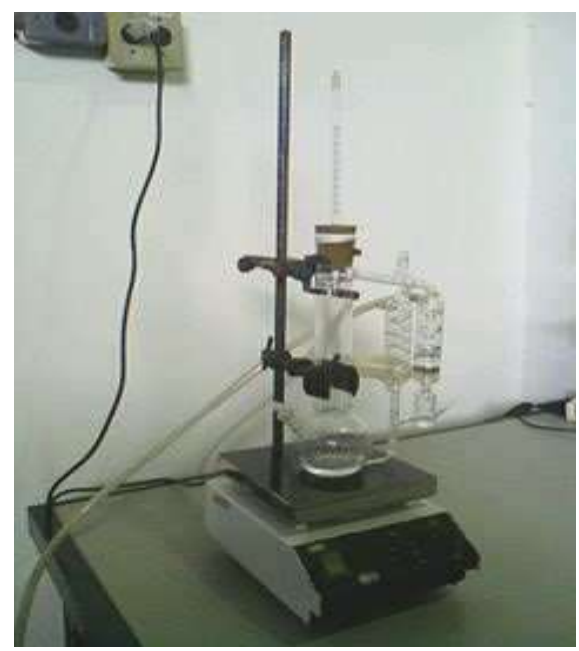

Figura 2 - Aparato experimental utilizado neste trabalho.

\section{Metodologia e Análise}

Antes de alimentar as soluções no ebuliômetro, este foi rinçado com etanol e seco através de uma placa de aquecimento. Alimentou-se o etanol, o glicerol e a água destilada, de acordo com a proporção exigida pelas concentrações estudadas. Pequenas esferas de vidro foram postas junto com a solução, a fim de controlar a ebulição. Após o início da circulação de água pelos condensadores do ebuliômetro, o aquecimento do sistema foi iniciado. A temperatura do ponto de ebulição foi monitorada em intervalos de 10 minutos e após a mesma permanecer constante durante 30 minutos, admitiu-se que o equilíbrio foi estabelecido. A partir desse momento, amostras da fase vapor foram coletadas e analisadas em um densímetro digital (Gehaka, DSL 920). Este densímetro utiliza o princípio do empuxo e apresenta erro experimental de $10^{-5}$. De posse da densidade das amostras, a concentração das mesmas foi obtida através de uma curva de 
calibração que descreve a variação da densidade por toda a faixa de concentração do sistema etanol-água. Todos os experimentos foram realizados em triplicata.

\section{RESULTADOS E DISCUSSÃO}

A fim de validar a metodologia experimental, foram medidos dados de equilíbrio do sistema etanol-água-glicerina utilizando concentrações de etanol e valores de $\mathrm{S} / \mathrm{F}$ iguais aos reportados por Lee e Pahl (1985). Estes autores trabalharam com razões de S/F diferentes para cada composição, variando de 2 ate 3,4, aumentando conforme a concentração de etanol aumentou. Os resultados encontram-se na Figura 3. Para melhor visualização, mostra-se apenas a região onde os dados estão agrupados (região mais concentrada em etanol), ou seja, a parte superior do diagrama $\mathrm{x}-\mathrm{y}$, já que os autores não trabalharam com soluções alcoólicas mais diluídas.

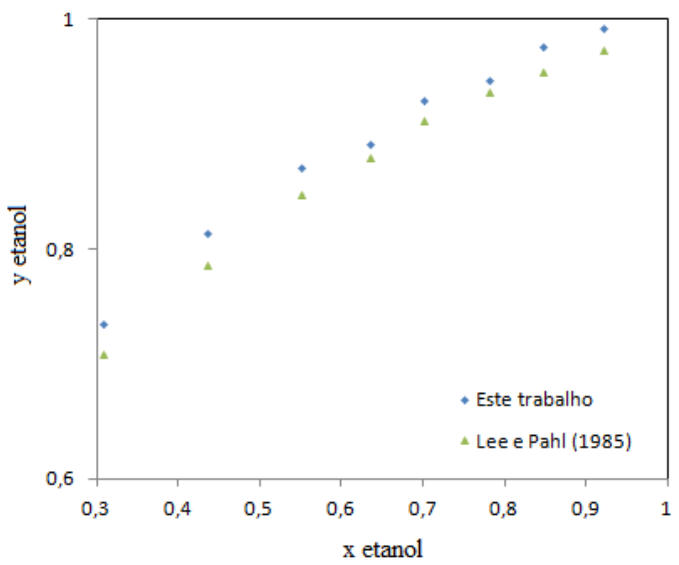

Figura 3 - Comparação entre os dados de ELV para o sistema etanol-água-glicerol experimentais e obtidos por Lee e Pahl (1985)

Como mostra a Figura 3, pode-se observar que os dados experimentais desse trabalho corroboraram com os da literatura (Lee e Pahl, 1985). O desvio médio relativo obtido foi de $2,32 \%$ na composição da fase vapor e 4,32\% na temperatura. Devido aos baixos desvios encontrados, considerou-se que a metodologia experimental foi validada.

Seguindo a metodologia, foram feitos experimentos variando-se a relação $\mathrm{S} / \mathrm{F}$ de 0,5 , 07, e 0,9. Os resultados encontram-se na Tabela 2. Estes resultados não puderam ser comparados com outros da literatura devido à ausência dos mesmos. Na Figura 4 é mostrado o equilíbrio líquido-vapor com os dados apresentados na Tabela 2. Nesta Figura ainda encontram-se os dados do sistema água-etanol (DECHEMA). Pode-se perceber, claramente, a 'quebra' do azeótropo pelo glicerol. Ainda, conclui-se desta Figura, que o glicerol melhora o comportamento para as regiões mais concentradas em etanol.

Tabela 2 - Resultados experimentais do ELV obtidos neste trabalho.

\begin{tabular}{|c|c|c|c|c|c|c}
\cline { 2 - 8 } \multicolumn{1}{c|}{} & \multicolumn{2}{c|}{ S/F: 0,5 } & \multicolumn{2}{c|}{ S/F: 0,7 } & \multicolumn{2}{c}{ S/F: 0,9 } \\
\hline $\begin{array}{c}\mathbf{x} \\
\text { etanol }\end{array}$ & $\begin{array}{c}\mathbf{y} \\
\text { etanol }\end{array}$ & $\begin{array}{c}\mathbf{T} \\
\left({ }^{\circ} \mathbf{C}\right)\end{array}$ & $\begin{array}{c}\mathbf{y} \\
\text { etanol }\end{array}$ & $\begin{array}{c}\mathbf{T} \\
\left({ }^{\circ} \mathbf{C}\right)\end{array}$ & $\begin{array}{c}\mathbf{y} \\
\text { etanol }\end{array}$ & $\begin{array}{c}\mathbf{T} \\
\left({ }^{\circ} \mathbf{C}\right)\end{array}$ \\
\hline 0,1 & 0,4882 & 85 & 0,60855 & 83,5 & 0,471 & 87,4 \\
\hline 0,2 & 0,6516 & 81 & 0,68037 & 80 & 0,6673 & 82,1 \\
\hline 0,3 & 0,6658 & 80 & 0,70466 & 79,5 & 0,7153 & 79,83 \\
\hline 0,4 & 0,7279 & 79 & 0,80049 & 79 & 0,7367 & 79 \\
\hline 0,5 & 0,7802 & 78,5 & 0,81828 & 78,6 & 0,7887 & 78,5 \\
\hline 0,6 & 0,8205 & 78,5 & 0,82595 & 78,2 & 0,8427 & 78 \\
\hline 0,7 & 0,8969 & 78 & 0,85881 & 78 & 0,8697 & 78 \\
\hline 0,8 & 0,9342 & 78 & 0,9109 & 78 & 0,9264 & 78 \\
\hline 0,9 & 0,9945 & 78 & 0,926 & 78 & 0,9986 & 78 \\
\hline
\end{tabular}

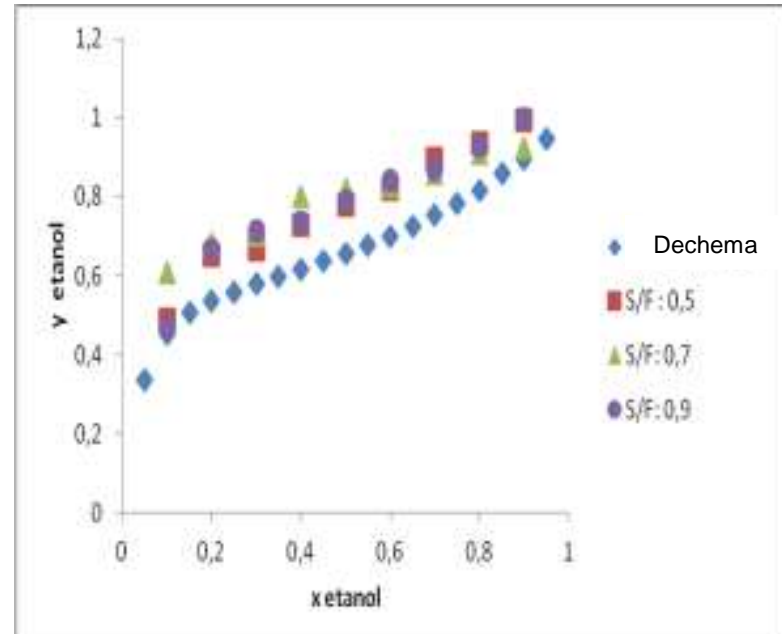

Figura 4 - Efeito da glicerina sobre o equilíbrio líquido-vapor do sistema etanol-água.

Esses dados foram tratados usando o modelo termodinâmico de NRTL e os desvios relativos foram baixos tanto para a temperatura quanto para a composição da fase vapor (Souza et al., 2013).

\section{CONCLUSÕES}

Este trabalho avaliou a influencia da glicerina no equilíbrio líquido-vapor do 
sistema água-etanol. Os resultados dos experimentos mostraram que o azeótropo entre o etanol e a água pode ser 'quebrado' pela glicerina, usando as relações solvente/carga utilizadas neste trabalho. A melhor visualização desta possibilidade se deu pela disparidade dos valores apresentados no desvio relativo médio, portanto conclui-se que a glicerina é um terceiro componente favorável, que ao ser adicionado ao sistema facilitou a quebra do azeótropo.

\section{REFERÊNCIAS}

AGENCIA SAFRA. Etanol: correios lançam selo homenageando liderança brasileira. Último segundo, 13 jan., 2009. Disponível em:

$<$ http://ultimosegundo.ig.com.br/economi a/safra/2009/01/13/+etanol+correios+lanc am+selo+homenageando+lideranca+brasil eira+3317998.html>. Acessado em 13/01/2009.

DECHEMA. Vapor-Liquid Equilibrium Data Collection, Aqueous-Organic Systems (Supplement 1), v. I, part 1a. GMEHLING, V. J.; ONKEN, U.; ARLT, W. Frankfurt/M., 1981.

FURTER, W.F. Extractive Distillation by Salt Effect. Extractive and Azeotropic Distillation. Advances in Chemistry series, 115, American Chemical Society, Washington, D.C., 1974.

GIL, I.D., UYAZAN, A.M., AGUILAR, J.L., RODRIGUEZ, G., CAICEDO, L.A. Separation of ethanol and water by extractive distillation with salt and solvent as entrainer: process simulation. Brazilian Journal of Chemical Engineering, vol. 25, no 1, p. 207-215, 2008.

LEE, F.M., PAHL, R.H. Solvent screening study and conceptual extractive distillation process to produce anhydrous ethanol from fermentation broth. Ind. Eng. Chem. Process Des. Dev., 24, p. 168-172, 1985.

LIDE, D.R., FREDERIKSE, H.P.R. $C R C$ Handbook of Chemistry and Physics, $74^{\text {th }}$ edition, CRC Press, 1991.

PRAUSNITZ, J.M., LICHTENTHALER, R.N., AZEVEDO, E.G. Termodinámica molecular de los equilibrios de fases. $3^{\mathrm{a}}$ edição, Prentice Hall Iberia, Madrid, 2000.

RAVAGNANI, M.A.S.S., REIS, M.H.M., FILHO, R.M., WOLF-MACIEL, M.R. Anhydrous ethanol production by extractive distillation: A solvent case study. Process Safety and Environmental Protection, 88, p. 67-73, 2010.

REID, R.C., PRAUSNITZ, J.M., POLING, B.E. The properties of gases \& liquids. $4 \mathrm{a}$ edição, McGraw-Hill, Inc., New York, 1987.

RIDDICK, J.A., BUNGER, W.B., SAKANO, T.K. Organic Solvents Physical Properties and Methods of Purification, $4^{\text {th }}$ Edition, Wiley, New York, 1986.

SOARES, R.B., (2010). Estudo da destilação extrativa salina em coluna de destilação recheada para a produção de etanol. Dissertação (Mestrado em Engenharia Química), DEQ, UFRRJ, Seropedica, 2009.

SOUZA, W.L.R., SILVA, C.S., MELEIRO, L.A.C., MENDES, M.F. Vapor-liquid equilibrium of the water-ethanol-glycerol system: experimental and modeling data at normal pressure, Journal of Chemical Thermodynamics, vol. 67, p. 106-111, 2013.

UYAZÁN, A.M., GIL, I.D., AGUILAR, J.L., RODRÍGUEZ, G., CAICEDO, L.A., Ing. Investig., vol. 26, p. 45-50, 2006.

\section{AGRADECIMENTOS}

À FAPERJ, pela bolsa concedida e apoio financeiro.

Ao CNPq, pelo apoio financeiro. 